Article

\title{
The Effect of Control Strategy on Tidal Stream Turbine Performance in Laboratory and Field Experiments
}

\author{
Carwyn Frost ${ }^{1, *(\mathbb{D})}$, Ian Benson ${ }^{1}$, Penny Jeffcoate ${ }^{2}$, Björn Elsäßer $^{3}{ }^{(1)}$ and Trevor Whittaker ${ }^{1}$ \\ 1 School of Natural and Built Environment, Queens University Belfast, David Keir Building, \\ Queen's University, Belfast BT7 1NN, UK; ian.benson@qub.ac.uk (I.B.); t.whittaker@qub.ac.uk (T.W.) \\ 2 Sustainable Marine Energy, Edinburgh EH6 6QW, UK; penny.jeffcoate@sustainablemarine.com \\ 3 Danish Hydraulics Institute (DHI), Ports and Offshore Technology, Agern Allé 5, 2970 Hørsholm, Danmark; \\ bje@dhigroup.com \\ * Correspondence: c.frost@qub.ac.uk; Tel.: +44-289-097-4012
}

Received: 9 May 2018; Accepted: 5 June 2018; Published: 12 June 2018

check for updates

\begin{abstract}
The first aim of the research presented here is to examine the effect of turbine control by comparing a passive open-loop control strategy with a constant rotational speed proportional-integral-derivative (PID) feedback loop control applied to the same experimental turbine. The second aim is to evaluate the effect of unsteady inflow on turbine performance by comparing results from a towing-tank, in the absence of turbulence, with results from the identical machine in a tidal test site. The results will also inform the reader of: (i) the challenges of testing tidal turbines in unsteady tidal flow conditions in comparison to the controlled laboratory environment; (ii) calibration of acoustic Doppler flow measurement instruments; (iii) characterising the inflow to a turbine and identifying the uncertainties from unsteady inflow conditions by adaptation of the International Electrotechnical Commission technical specification (IEC TS): 62600-200. The research shows that maintaining a constant rotational speed with a control strategy yields a $13.7 \%$ higher peak power performance curve in the unsteady flow environment, in comparison to an open-loop control strategy. The research also shows an $8.0 \%$ higher peak power performance in the lab compared to the field, demonstrating the effect of unsteady flow conditions on power performance. The research highlights the importance of a tidal turbines control strategy when designing experiments.
\end{abstract}

Keywords: tidal energy; experimental testing; acoustic Doppler profiler; Strangford Lough

\section{Introduction}

The economic feasibility of offshore wind energy has reached unprecedentedly low strike prices in the recent Contracts for Difference (CfD) auction in the UK at $157.50 /$ MWh in 2022/23, dropping 43\% since 2012 [1]. The offshore renewable energy sector must drive to deliver other significant technologies that can achieve competitive levelised cost of electricity (LCOE). To deliver further cost reductions in an economically sustainable manner, developers must improve their technical understanding of a technology and gain experience of its performance in the real marine environment.

Even though numerical models and various design codes and methods for rotational power generators such as wind turbines and hydropower turbines are well established and in general yield excellent results, these models still require validation through experimental testing $[2,3]$. It is noted from this model scale testing that Reynolds independence is a key consideration for non-dimensional comparison.

To date there is limited published research on the experimental testing of prototype devices in the marine environment. However, Gaurier et al. [4] published a study comparing the test results from the 
same turbine undertaken in different lab facilities. They conclude that turbulence characteristics in lab facilities need to be described more adequately to better assess performance results. Furthermore, Mycek et al. studied the effect of turbulence intensity on a model turbine in a circulating flume. The range of turbulence intensities used (3\% and 15\%) may be typical of what is found at a tidal test site and the results show that this change in intensity has a near negligible effect on the time averaged performance of the turbine [5].

To support the industry in understanding the challenges of tidal turbine performance assessment a series of studies have been undertaken by Queen's University Belfast at a significant scale in tank, lake and tidal environments. The experimental campaigns are described in Table 1 and related publications are cited.

Table 1. Tidal Turbine Testing (TTT) project history.

\begin{tabular}{|c|c|c|c|c|}
\hline Project & Date & & Experiment Description & Publications \\
\hline TTT & 2013-2014 & $\circ$ & $\begin{array}{l}\text { Tandem pushing tests in Montgomery Lake } \\
\text { Moored tandem tests in Strangford Narrows }\end{array}$ & [6-8] \\
\hline TTT 2 & 2014-2015 & $\circ$ & $\begin{array}{l}\text { MaRINET (Marine Renewables Infrastructure Network) } \\
\text { transnational access to Consiglio Nazionale delle } \\
\text { Ricerche-Istituto nazionale per studi ed esperienze di } \\
\text { architettura navale (CNR-INSEAN) for turbine tests } \\
\text { MaRINET transnational access to Strangford Narrows for } \\
\text { SCHOTTEL Hydro STG } 50 \text { turbine (SCHOTTEL, } \\
\text { Spay, Germany) tests }\end{array}$ & [9-12] \\
\hline TTT 3 & 2015-2017 & $\circ$ & $\begin{array}{l}\text { Moored single turbine testing in Strangford Narrows } \\
\text { Towing tank testing in CNR-INSEAN with Wave and } \\
\text { Yaw Angles }\end{array}$ & [13] \\
\hline
\end{tabular}

From this previous research and literature review it has been reported that experimental testing in an unsteady marine environment results in power performance disparities when compared with steady flow testing. Jeffcoate et al. [7] reports a $24 \%$ reduction in $C_{P}$ between steady and unsteady flows. Meanwhile, Starzmann et al. [11] report comparable power performance between steady and unsteady flows (only a $5 \%$ change in $C_{P}$ ); however, the thrust performance was higher in the unsteady conditions relative to the steady conditions. In addition to this previous work, applicable studies have been conducted by other groups at a similar scale. The work of Forbush et al. [14] reports an $8 \%$ increase in performance with turbulent flow; however, the cross-flow tidal turbine used in this research sets it apart as a unique result, which may be specific to the rotor type. Blackmore et al. [15] performed repeat experiments in a circulating flume, the inflow characteristics were varied using a grid. The inflow velocity was maintained, while the Turbulence Intensity (TI) and length scale varied. The findings showed a $10 \%$ reduction in $C_{P}$ with an increase in TI, conversely an increase in length scale resulted in an increase in $C_{P}$.

In all field experiment cases, the cause of power disparity between lab and field is partly attributed to uncertainty in the experiments. Further consideration of the source of uncertainty has identified two critical contributing factors:

i. A crucial factor in the accuracy of performance measurements arises from the control strategy imposed on the tidal turbine. The capability of the control system to keep the rotor operating near its optimum Tip Speed Ratio (TSR), when driven by an unsteady and non-uniform inflow velocity, and avoiding 'stall', is a key element in a successful commercial turbine. Similarly, the control strategy adopted during an experiment can increase the error bounds in derived performance indicators, such as $C_{P}$. Control strategies used in previous tidal turbine performance testing vary. For devices at low Technology Readiness Level (TRL) scales [16], such as those used in laboratory scale experiments, an open-loop control may suffice [9]. However, more commonly, a closed-loop, proportional-integral-derivative (PID) 
feedback control strategy is found $[17,18]$ in higher TRL devices. It is recognised that in order to develop the industry, advanced control strategies require development and testing in highly parameterised conditions. Efforts are being made in this field in both research and industry. The use of overspeed, pitch or stall control strategies with peak power tracking, or surface mapping algorithms for condition monitoring purposes are under development $[19,20]$. Furthermore, future options may include the possibility of feed-forward algorithms such as those being trialled in the wind sector [21].

ii. The second source of increased uncertainty comes from the increased variability of the inflow velocity. This is of particularly significance since the power density scales with the cube of the inflow velocity. Furthermore, both genuine variability and sampling errors are compounded in real velocimetry data. Separating and quantifying their effects requires care in calibration of instruments and data analysis. In order to promote consistent best practice in the power performance testing of Tidal Energy Converters (TECs), Johnstone et al. published best practices for the wave and tidal sector [22] which specifies the requirements for clear uncertainty analysis. Further to this the IEC (Geneva, Switzerland) published a Technical Specification IEC/TS 62600-200 [23]. The specification provides the methodology for determining an average value for velocity at a site, enabling the time average performance of a turbine to be captured and reported to a common standard. The IEC specification has been used in other research projects and across the industry $[10,13,24]$ and will be used to guide the data analysis in this paper.

In summary, the literature review has highlighted experiments where turbine testing in the lab has been compared to the field. The control strategy and inflow measurements are significant parameters that must reflect the device TRL and testing environment. In order to inform the sector of the significance of these parameters, the TTT turbine will be deployed in the lab and field, the derived performance results will be compared for two control strategies, and in a steady and unsteady inflow environment. The lab experiments will be used as an opportunity to calibrate and derive uncertainty metrics for the inflow, this will then be applied to the field experiments and performances compared.

\section{Experimental Setup}

Under the TTT 3 project, both the laboratory and field tests were conducted using the same instrument, maintaining continuity between experiments. This was achieved by using the same turbine, velocity instruments and data acquisition system. The laboratory experiments were undertaken in the controlled steady environment of the towing tank facility CNR-INSEAN, Italy. The field test experiments were performed in the uncontrolled, unsteady environment of the tidal test site in Strangford Narrows, Northern Ireland (Lat.: $54.381801^{\circ}$, Long.: $-5.556743^{\circ}$ ).

The $1.5 \mathrm{~m}$ diameter turbine is pictured during operations in Strangford Lough in 2016 (Figure 1); the device dimensions can be found in the supplementary appendix of previous work [6] and remain consistent in this work. The rotor blades are an Eppler E387 airfoil geometry, each blade is $0.575 \mathrm{~m}$ long and features a pitch distribution similar to industrial wind turbine blades, with a root pitch angle of $32^{\circ}$ which recedes to $13^{\circ}$ at the tip of the blade. As this is not a commercial blade and is not designed to be scaled the significance of Reynolds independency is limited.

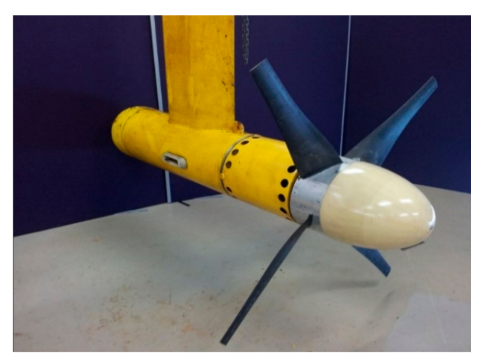

Figure 1. Tidal Turbine Testing (TTT) device and rotor. 


\subsection{Flow Instrumentation}

Acoustic Doppler profilers (ADPs) are often used for tidal flow resource assessment, and are the given method for characterising inflow conditions by the IEC [23]. The Nortek $2 \mathrm{MHz}$ 'Aquadopp' used in the experiments was the primary instrument for determining inflow velocity in these experiments.

The experimental setup shown in this section relates to all work as part of the TTT 3 project. Please refer to referenced papers for further details on previous experimental setups [6,9]. The supporting gantry also hosts a Nortek 'Vector' Acoustic Doppler Velocimetry (ADV) with the sample volume located at the apex of swept area at $16 \mathrm{~Hz}$, this provided insight into the inflow turbulence. The deployment parameters for both instruments are given below. In accordance with the IEC standards for power performance assessment, the inflow measurements were taken at an upstream distance of between 2-5 equivalent diameters from the plane of rotation [23].

The geometrical setup can be seen in Figure 2 and is detailed in Table 2, where the parameter D2 has two values: one for the towing tank and one for Strangford Lough tests, respectively. This difference was due to the location of suitable mounting points in the towing carriage.

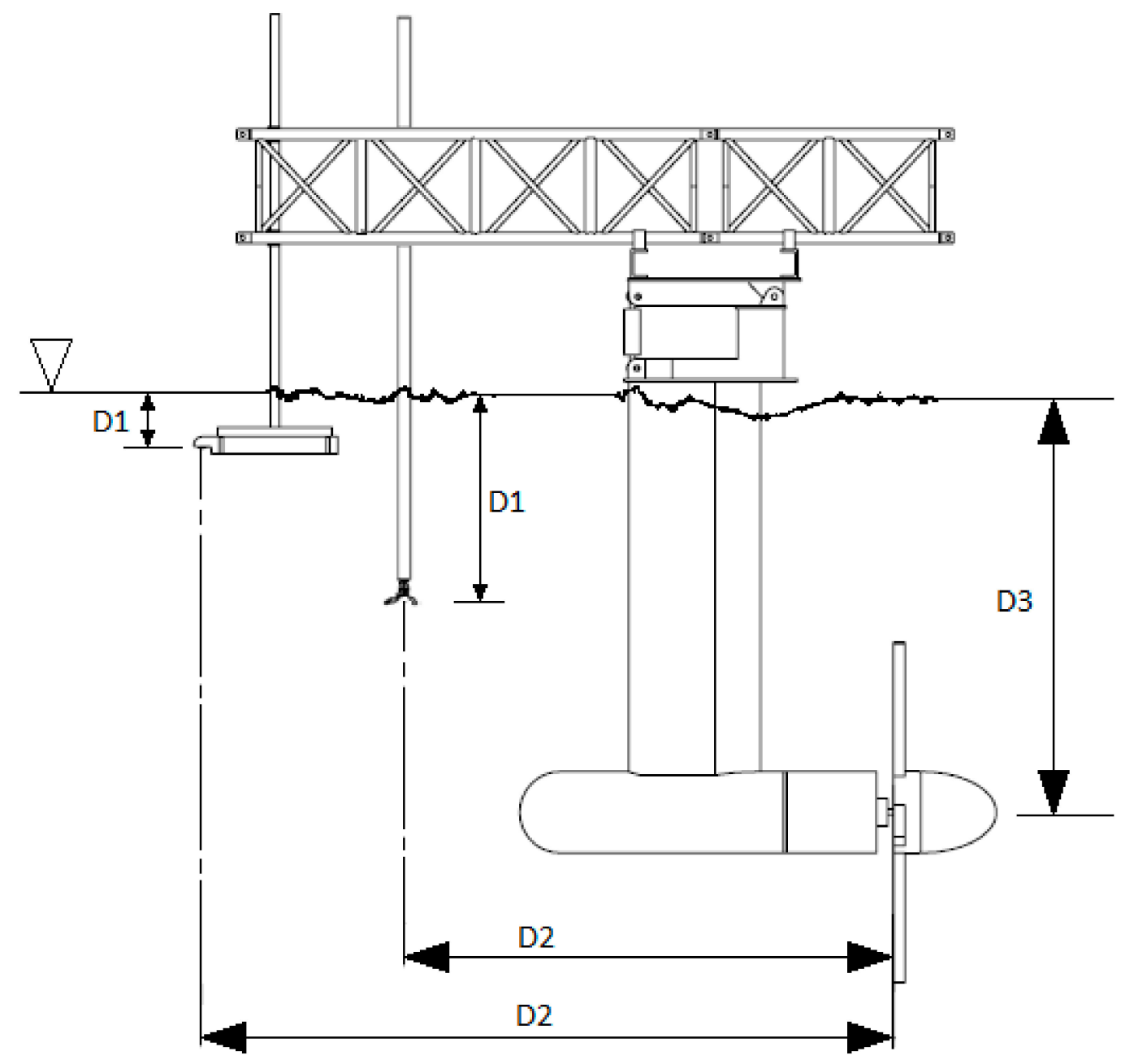

Figure 2. Turbine, Acoustic Doppler profiler (ADP) and Acoustic Doppler Velocimetry (ADV) deployment Configuration. 
Table 2. Turbine, Acoustic Doppler profiler (ADP) and Acoustic Doppler Velocimetry (ADV) deployment parameters.

\begin{tabular}{ccccc}
\hline \multirow{2}{*}{ Parameter } & \multicolumn{2}{c}{ ADP } & \multicolumn{2}{c}{ ADV } \\
\cline { 2 - 5 } & Strangford & CNR-INSEAN & Strangford & CNR-INSEAN \\
\hline Distance D1 (m) & $0.30 \mathrm{~m}$ & $0.30 \mathrm{~m}$ & $0.86 \mathrm{~m}$ & $0.86 \mathrm{~m}$ \\
Distance D2 (m) & $2.99 \mathrm{~m}$ & $3.80 \mathrm{~m}$ & $3.10 \mathrm{~m}$ & $3.7 \mathrm{~m}$ \\
Distance D3 (m) & $1.75 \mathrm{~m}$ & $1.75 \mathrm{~m}$ & $1.75 \mathrm{~m}$ & $1.75 \mathrm{~m}$ \\
Power & high & high & high & high \\
Transmit length & N/A & N/A & $8 \mathrm{~mm}$ & $8 \mathrm{~mm}$ \\
Number of cells & 20 & 20 & $\mathrm{~N} / \mathrm{A}$ & $\mathrm{N} / \mathrm{A}$ \\
Cell Size (m) & $0.25 \mathrm{~m}$ & $0.25 \mathrm{~m}$ & $\mathrm{~N} / \mathrm{A}$ & $\mathrm{N} / \mathrm{A}$ \\
Blanking Distance (m) & $0.25 \mathrm{~m}$ & $0.25 \mathrm{~m}$ & $\mathrm{~N} / \mathrm{A}$ & $\mathrm{N} / \mathrm{A}$ \\
Co-ordinate System & Beam & Beam & Beam & Beam \\
Sample Frequency & $1 \mathrm{~Hz}$ & $1 \mathrm{~Hz}$ & $16 \mathrm{~Hz}$ & $16 \mathrm{~Hz}$ \\
(Hz) & $120-600 \mathrm{~s}$ & $90-140 \mathrm{~s}$ & $120-600 \mathrm{~s}$ & $90-140 \mathrm{~s}$ \\
Sample Period (s) & & & &
\end{tabular}

\subsection{Flow Instrumentation Validation}

Many ADP instruments have previously been independently calibrated and validated to verify the quality of factory settings. Shih et al. [25] demonstrated the close agreement between calibrations for two different ADP suppliers, RDI (Poway, CA, USA) \& SonTek (San Diego, CA, USA) in a towing tank facility in 2000. More recently, Oberg et al. [26] performed similar experiments with the most recent instrument firmware, again using RDI and SonTek instruments. Little work has been found which independently calibrates the Nortek Aquadopp ADP used in this experiment; however, Elsäßer et al. showed discrepancies in time averaged velocities of up to $0.19 \mathrm{~ms}^{-1}$ between two instruments collocated in the field [27]. In order to ensure instrument accuracy, the ADP (2 MHz Aquadopp) was calibrated during the towing tests under conditions as close as were possible to the field. Seeding of the towing tank was required to improve the Signal to Noise Ratio (SNR).

To validate this ADP calibration against another independent instrument while working in the field, the Nortek Vector ADV was likewise calibrated during the tank work. $16 \mathrm{~Hz}$ Vector data was averaged over 1-s bins to match the ADP (2 MHz Aquadopp) data bins. All the calibration results are given in Table 3 and show the deviation of the instruments from their factory calibration. Each calibration equations were derived for $\mathrm{U}, \mathrm{V}$ and $\mathrm{W}$ from the towing tests for the Aquadopp (ADP) and Vector (ADV) instruments. The linear equations demonstrate the precision and bias drift since the previous calibration (in $\mathrm{mm} / \mathrm{s}$ ) as yielded by the Nortek transform matrices for each instrument. Note the signs are chosen to make the output components have the same axis convention for both instruments. $\mathrm{U}$ is the main direction of inflow, along the turbine axis.

Table 3. Deviation of Nortek instruments from factory calibration.

\begin{tabular}{ccc}
\hline Nortek Transform Matrix Output & ADP-Aquadopp & ADV-Vector \\
\hline $\mathrm{x}$ & $\mathrm{U}=-1.0124 \mathrm{x}+4.97$ & $\mathrm{U}=-1.0042 \mathrm{x}+6.4$ \\
$\mathrm{y}$ & $\mathrm{V}=-1.0124 \mathrm{y}+0$ & $\mathrm{~V}=+1.0042 \mathrm{y}+0$ \\
$\mathrm{z}$ & $\mathrm{W}=-1.0124 \mathrm{z}+0$ & $\mathrm{~W}=-1.0042 \mathrm{z}+0$ \\
Bias in $\mathrm{U}(1 \sigma)$ & $-0.03 \%$ & $+0.05 \%$ \\
Precision in $\mathrm{U}(1 \sigma)$ & $\pm 0.6 \%$ & $\pm 0.9 \%$ \\
\hline
\end{tabular}

In summary, the calibration performed in the towing tank agrees closely with the factory calibration, showing less than a percentage difference in bias and precision. The same individual instruments, deployment parameters and locations were used during both the laboratory and fieldwork testing. Further validation of the results has been undertaken using the fieldwork data, further detail 
can be found in Appendix A. This provides confidence in instrument accuracy and draws attention to the high spatial variability in tidal flows, as discussed by Elsäßer et al. [27].

\subsection{Control Strategy}

The control of wind turbines is an established and mature area of technology. The control strategy involves multiple inputs and outputs [28] and more than one control loop, often extending to variables intended to optimise the performance of an array and its grid interface.

In contrast, the original TTT 2 experimental design was an open-loop load control, as shown in Figure 3. Control was provided by a binary array of resistors ( 5 values, each the double of the previous: $10.25 \mathrm{ohms}, 20.5 \mathrm{ohms}$ etc.). Thus, 32 load values could be placed on the DC-bus by switching combinations in and out. Electromechanical contactors select the load on command from the central Data Acquisition System (DAQ), based on a National Instruments Compact Rio (cRio) running Labview and further custom-made interface electronics and cabling.

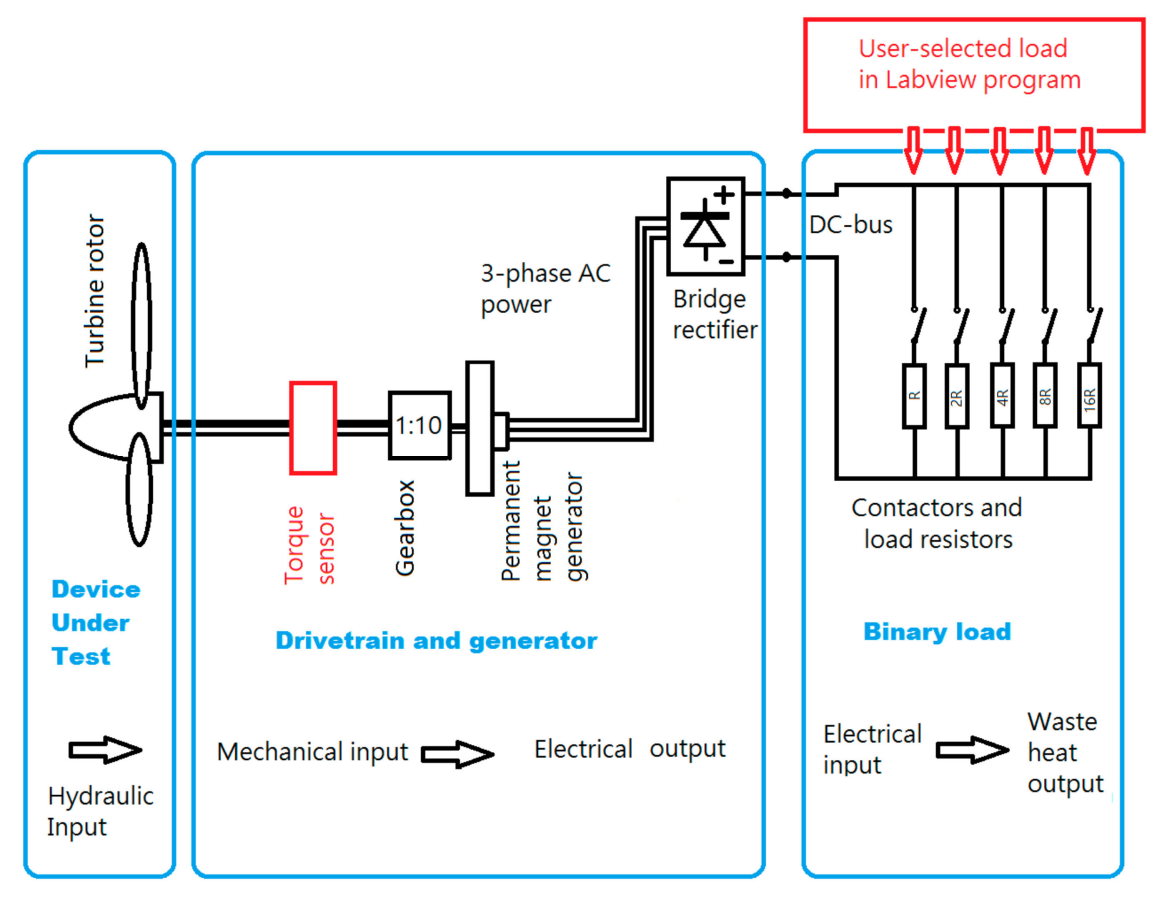

Figure 3. TTT 2 open-loop control and binary load.

In developing the control system, a single control loop was included with only one process variable as the input (the rotor shaft speed) and one output (the electrical demand placed on the alternator). A review of Proportional-Integral-Derivative (PID) control theory, developed in the mid 20th century, is presented by Bennet [29]. In order to incorporate a closed-loop PID load control, a linear regulator was used to place an electronic load on the turbine at the DC output terminals. The upgraded PID control loop is shown in Figure 4. An absolute rotary encoder was included to provide higher resolution of shaft speed for the PID loop.

The PID control system was run as a Labview virtual instrument in the DAQ programme, which was written specifically for the project. Most of the programme's other features were identical for both TTT 2 (open-loop) and TTT 3 (PID; see Table 1 for project details). To control the turbine for the TTT 3 system, the user selects a chosen shaft speed (set point) and the system then attempts to maintain that speed independently of flow features in the field, or of towing speed in the laboratory. The PID parameters used were identical in both the field and towing tank; all the results under PID control were collected with the parameters set as in Table 4. 


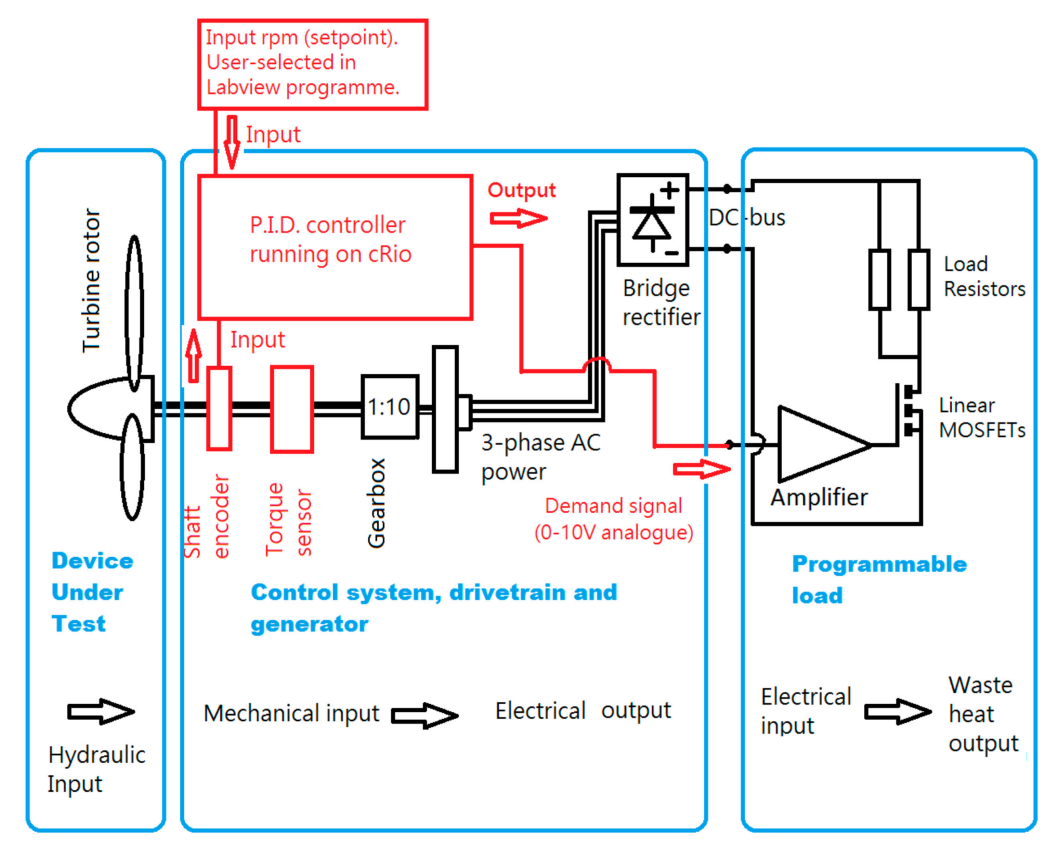

Figure 4. TTT 3 closed-loop Proportional-Integral-Derivative (PID) control and programmable load.

Table 4. Proportional-Integral-Differential parameters.

\begin{tabular}{ccc}
\hline Symbol & Description & Value \\
\hline $\mathrm{Kc}$ & Proportional constant & 2.2 (no dimensions) \\
$\mathrm{Ti}$ & Integration time constant & $0.003(\mathrm{~min})$ \\
$\mathrm{Td}$ & Differential time constant & $0.001(\mathrm{~min})$ \\
\hline
\end{tabular}

The proportional constant, Kc or gain was either positive or negative, depending on the rotational direction of the driveshaft. This also applied to the set RPM (Rotations per Minute) value in the control system. The tuning of the loop parameters was done in the field with the Zeigler and Nichols 'ultimate cycling' method [30], followed by some minor optimisation by trial and error. It is worth noting that the ultimate cycling method gave adequate robustness and precision of control for our purposes and was only slightly adjusted with subsequent trial and error.

\section{Non-Dimensional Performance Characteristics}

As previously noted, the DAQ features a National Instrument Compact Rio, the cRio synchronises the various instrument and control data streams into a common format, timestamps them and outputs them as a data file for post-processing.

To compare and analyse the performance of the turbine between the various experimental campaigns, the non-dimensional performance characteristics will be derived. These are shown in Equations (1) and (2) and provide the Tip Speed Ratio (TSR) and Coefficient of Power $\left(C_{P}\right)$.

$$
\begin{gathered}
\operatorname{TSR}_{i}=\frac{\bar{\omega}_{i} \times r}{\bar{U}_{i}} \\
C_{P, i}=\frac{\bar{P}_{i}}{\frac{1}{2} \times \rho \times A \times \bar{U}_{i}{ }^{3}}
\end{gathered}
$$

where the rotational speed of the turbine $\omega$ was in $\mathrm{rad} / \mathrm{s}$, the turbine radius, $r=0.75 \mathrm{~m}$, water density, $\rho=1025 \mathrm{~kg} / \mathrm{m}^{3}$ and the turbine area, $A=1.767 \mathrm{~m}^{2}$. The mean power, $\bar{P}$ was derived from the product of the rotational speed and mechanical torque measurements averaged over the period of the 
test window. Both non-dimensional performance indicators require a value for the inflow velocity to the turbine $\left(\bar{U}_{i}\right)$. To derive the mean current velocity, the method of bins, employed by the IEC 62600:200 [23], was used. This method has been outlined in previous work; however, the method has since been developed by the authors to account for bias introduced by the Doppler noise and thus determine the associated uncertainty in the inflow velocity. Further detail on the method and its development can be found in Appendix B and previous research [13].

\section{Results}

The following section is presented in two subsections, time series results and derived performance (time averaged) results. In each subsection, the comparison between field and lab results will be made and a comparison of the two turbine control strategies (open loop and PID control).

\subsection{Time Series Results}

Figure 5 is a time series plot comparing the experimental data in the field (Strangford Lough) and the lab (CNR-INSEAN); the two experimental setups feature the PID controller and were conducted under the TTT 3 experiments in 2016/17. Turbine rotational speed, fluid inflow velocity and turbine output power are plotted as time series. Figure 5 a shows the rotational velocity from the PID controller was set to 50 RPM for the field and lab. The stability in both sets of results are good with standard deviations of $2 \sigma_{\mathrm{RPM}}=1.57$ and 0.45 respectively for the field and lab. Subplot (b) shows the relative velocity of the water passing the turbine. One of the challenges of ADP and ADV deployments in towing tanks is maintaining a sufficient level of seeding in the water to suit the acoustic reflection and achieve strong SNR, this is not an issue in the field. For the lab velocity, the carriage encoder was used to derive the velocity and subsequent performance characteristics. The ADP results from the field show high flow variation $\left(2 \sigma_{\mathrm{Vel}}=0.18\right)$ and this instability is carried through to the mechanical power of the turbine (see Figure $5 c$, while the steady conditions in the lab result in a steady power output.

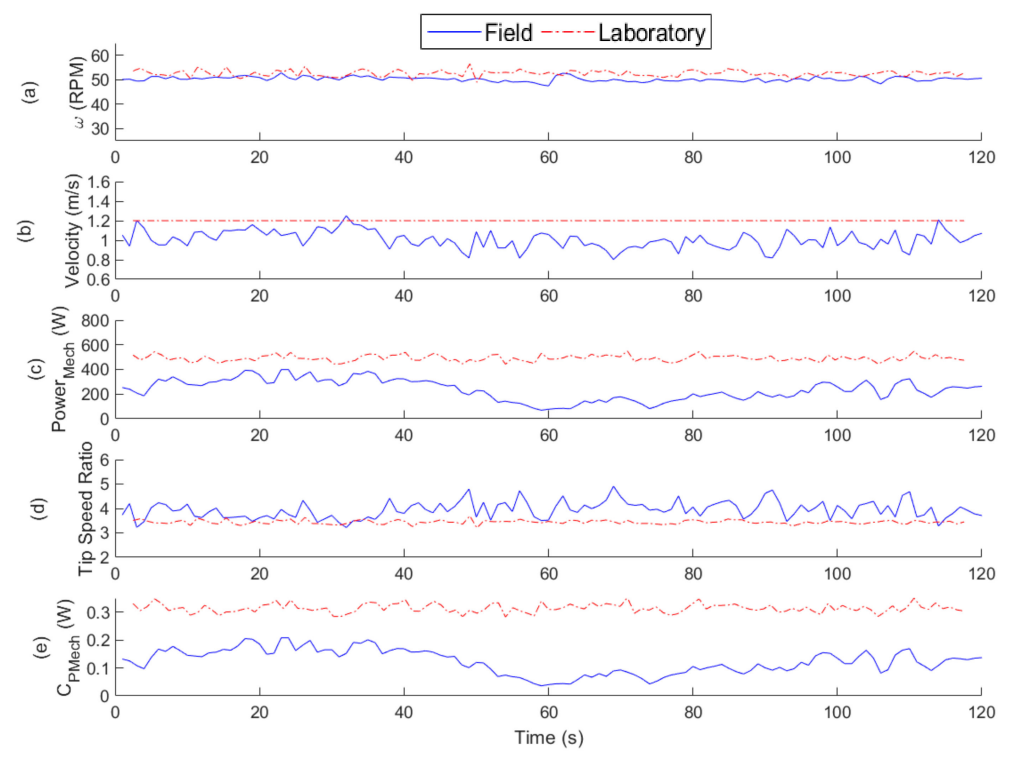

Figure 5. Time series plot of (a) turbine rotational speed; (b) inflow velocity; and (c) mechanical power. (d) Tip Speed Ratio and (e) Coefficient of Mechanical Power using PID controller in the lab and field.

The derived non-dimensional performance characteristics are shown in subplots (d) and (e). For the field results it is clear the TSR fluctuates with the inverse of the inflow velocity as expected. More significantly, the slight difference in TSR results in a significant difference in the $C_{P}$. The lab results have a stable TSR and $C_{P}$ with $2 \sigma_{\mathrm{TSR}}=0.16$ and $2 \sigma_{\mathrm{CP}}=0.03$, while the fluctuating field results have lower mean value and higher standard deviation $\left(2 \sigma_{\mathrm{TSR}}=0.70\right.$ and $\left.2 \sigma_{\mathrm{CP}}=0.07\right)$. 
Figure 6 shows the time series results from the open loop controller and PID controller from Strangford Lough field campaigns in TTT and TTT 3. Time series were selected which had the same time-averaged velocity and the time series (and thus average) extends to circa four minutes in both cases. The TTT deployment in 2013 used an open loop control strategy setting a constant demand torque to the alternator, while the TTT 3 deployment in 2016 used the PID (closed loop) control strategy with a set RPM, fluctuating the demand torque to maintain the constant RPM. Note the PID Control case exhibits the same results as shown in Figure 5. The open-loop control RPM time series (Figure 6a) has a higher standard deviation $\left(2 \sigma_{\mathrm{RPM}}=6.37\right)$ than the equivalent closed-loop control time series $\left(2 \sigma_{\mathrm{RPM}}=1.49\right)$. However, maintaining a constant RPM does not result in a constant power output due to the fluctuations in the inflow velocity as shown in Figure $6 \mathrm{~b}$. The inflow velocity for both experiments is derived from the IEC method of bins using the ADP data, as described previously. The mechanical power time series, Figure $6 c$, shows little difference in signal fluctuation between the two control methods, as confirmed by the standard deviations $\left(2 \sigma_{\text {Power }}=110.58\right.$ and 109.88 respectively for open and PID control). The cause of the fluctuations has now been isolated to the inflow velocity fluctuations, as opposed to the type of control strategy, and can be considered independent of fluctuations in RPM. The further significance of these two control strategies can be seen in the derived performance characteristics. Figure 6d,e show the TSR and $C_{P}$ it is clear that while the PID experiences a more stable TSR value $\left(2 \sigma_{\text {TSR }}=1.02\right.$ and 0.70 Open and PID control respectively) the $C_{P}$ for both control strategies have similar fluctuations $\left(2 \sigma_{\mathrm{CP}}=0.06\right.$ and 0.07 Open and PID control respectively).
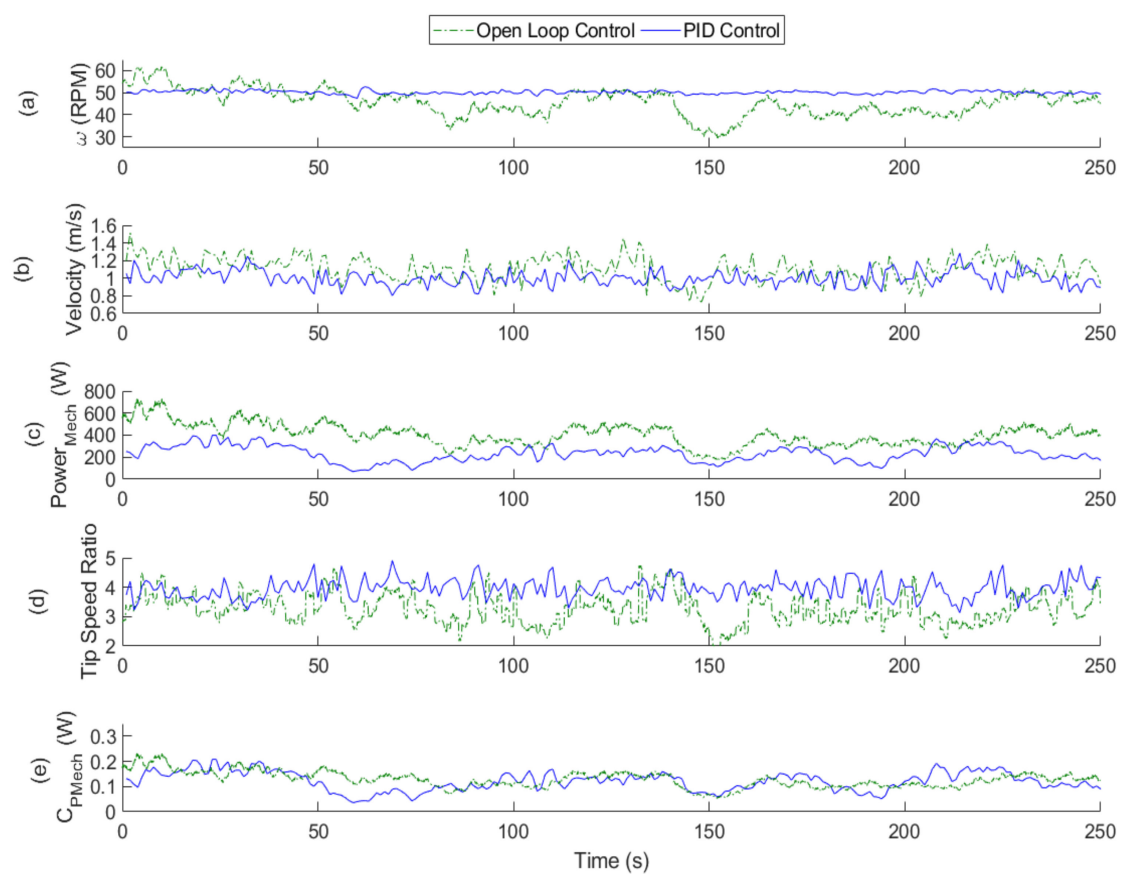

Figure 6. Strangford Lough time series plot of (a) turbine rotational speed; (b) inflow velocity; and (c) mechanical power. (d) Tip Speed Ratio (e) Coefficient of Mechanical Power.

\subsection{Derived Performance Results}

The power performance characteristics of the Eppler rotor using the same experimental setup and PID control settings in CNR-INSEAN and Strangford Lough are shown in Figure 7. The varying inflow experienced at Strangford Lough has been plotted in the figure using $0.1 \mathrm{~ms}^{-1}$ velocity bins associated with each of the time averaged reading (this is in accordance with the IEC standard [23]). Two trends are noted in to the uncertainty bounds; firstly, with increasing TSR, the uncertainty increases. This indicates the uncertainty from rotational speed, $\omega$ and inflow velocity $\bar{U}_{i}$ are the dominating sources. Secondly, the uncertainty bounds for low velocity bins $\left(\mathrm{U}_{0.8}-\mathrm{U}_{1.0}\right)$ are comparably greater than higher velocity 
bins $\left(\mathrm{U}_{1.1}-\mathrm{U}_{1.4}\right)$ at the same or similar TSR values. This may be due to the Signal to Noise Ratio (SNR) of the instrument being poor at these lower velocities, increasing uncertainty. The two curves show very close agreement at low TSR; however, as the power curves reach their peak, there is an $8.0 \%$ difference in $C_{P}$ and a $4.5 \%$ difference in the TSR for peak $C_{P}$. The separation between the curves is maintained as the turbine approaches freewheeling. The uncertainty bounds in the results overlap, but there is also a number of data points well below the performance curve. This deficit in power performance is due to the unsteady inflow parameters and this outcome agrees with Starzmann et al. [11] and is also comparable with results from the flume experiments by Blackmore et al. [15]. This shows that turbine power performance is adversely affected by unsteady inflow. Further consideration of the inflow turbulence metrics and their significance on hydrodynamic performance must be considered.

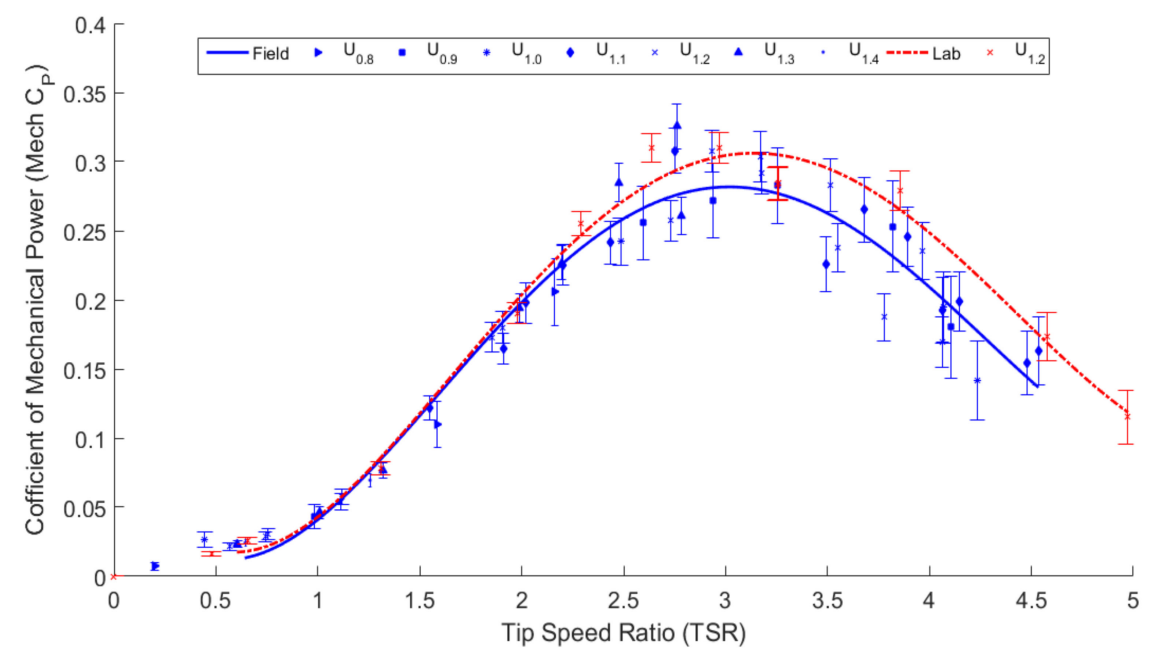

Figure 7. Mechanical Power performance for Eppler Rotor in the lab and field using PID Controller.

In its nature, a tidal test site will have a significantly varying inflow, this can be seen by the data points corresponding to the average velocity over which they were taken. Table 5 further shows this variation in velocities in accordance with the IEC standards for power performance of a tidal turbine [23]. Each data set in the velocity bins comes from a time averaged result of at least $2 \mathrm{~min}$.

Table 5. Tabulated results for Strangford Lough.

\begin{tabular}{ccccc}
\hline $\begin{array}{c}\text { Velocity Bin } \\
\left(\mathbf{m s}^{-\mathbf{1}}\right)\end{array}$ & $\begin{array}{c}\text { Mean Current } \\
\text { Velocity, }\left(\overline{\boldsymbol{U}}_{\boldsymbol{i}}\right)\end{array}$ & $\begin{array}{c}\text { Mean Power } \\
\text { Output, }\left(\overline{\boldsymbol{P}}_{\boldsymbol{i}}\right)\end{array}$ & $\begin{array}{c}\text { Mean SD of Power } \\
\text { Output, }\left(\overline{\mathrm{SD}}_{\boldsymbol{P}}\right)\end{array}$ & $\begin{array}{c}\text { Number of } \\
\text { Data Sets, } \boldsymbol{n}\end{array}$ \\
\hline $0.65-0.75$ & 0.720 & 37.972 & 7.088 & 3 \\
$0.75-0.85$ & 0.802 & 100.929 & 45.999 & 6 \\
$0.85-0.95$ & 0.922 & 113.202 & 59.554 & 4 \\
$0.95-1.05$ & 1.012 & 193.498 & 94.951 & 13 \\
$1.05-1.15$ & 1.100 & 215.158 & 91.195 & 16 \\
$1.15-1.25$ & 1.183 & 264.867 & 78.834 & 8 \\
$1.25-1.35$ & 1.254 & 83.518 & 15.557 & 2 \\
\hline
\end{tabular}

In Figure 8, the average mechanical power performance of the PID control system can be seen to have a higher performance curve than the equivalent open loop control system. At peak performance, the PID control turbine is $13.7 \%$ more efficient than the open-loop control turbine. 


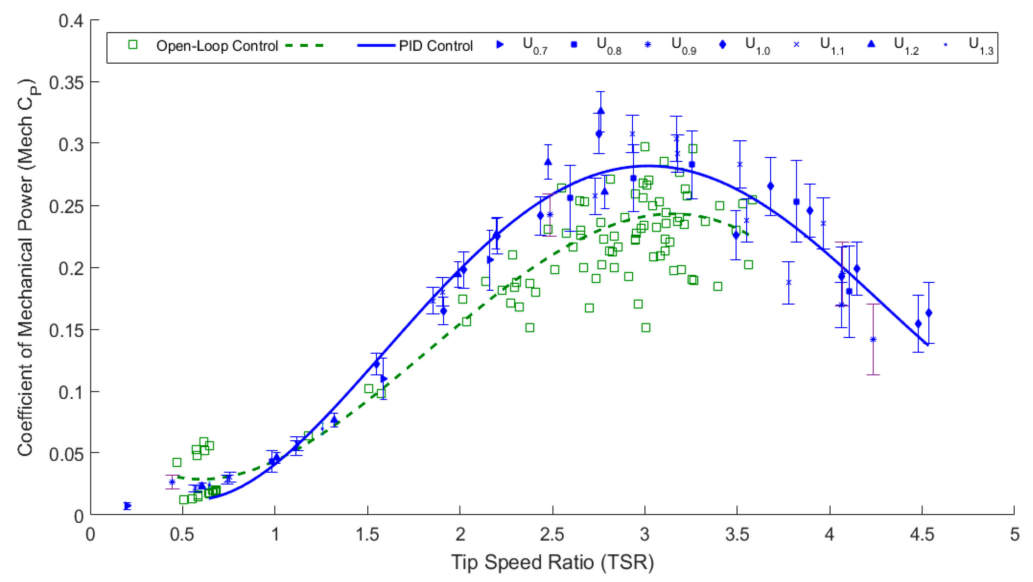

Figure 8. Mechanical Power Performance of turbine in Strangford Lough using two control strategies.

In addition to the increase in performance, the inclusion of the closed-loop control system improves the distribution of the data points across the $C_{P}$-TSR curve. The open-loop control results have greater scatter, resulting in a comparatively poorer fit $\left(R^{2}=0.84\right.$ and 0.96 for Open and PID Control respectively, Degrees of Freedom $=4$ ). Furthermore, on the right-hand side of the curve, the closed-loop control system has reached a higher TSR, providing a fuller picture of the Eppler rotor performance curve, this is due to the control system having a higher variability in resistance, thus getting closer to freewheeling.

\section{Discussion}

The comparison of performance in turbine response during experiments in the lab and field show that the performance characteristics do change in the presence of unsteady inflow conditions. While there is a performance drop in $C_{P}$ between the lines of best fit of the steady lab conditions and the unsteady field conditions, the uncertainty bounds of the data points overlap suggesting the difference is with the region of uncertainty. In order to improve these uncertainty bounds, it is suggested that increasing the number of samples/sample rate or increasing the number of bins in the projected area of the rotor is required. These options are limited when using an ADP due to their correlation with the Doppler noise source. This highlights the importance of instrument selection and setup for deriving the inflow performance.

The method used to account for uncertainties shows robustness in its application in the field and lab. The use of ADPs to measure inflow in the field is appropriate in high flow environments, when characterising full-scale turbine performance, in accordance with the IEC standard. However, awareness of the ADPs' contribution to uncertainty in the derived performance characteristics is important. Due to the difficulty in maintaining sufficient seeding material in towing tanks, the appropriateness of ADPs remains a challenge; however, as shown in steady flow conditions, the carriage velocity is sufficiently accurate. Alternatively, Particle Image Velocimetry (PIV) measurements would be the favoured method in towing tanks.

The comparison of the PID controller with a set RPM and open-loop controller in unsteady inflow conditions (Strangford Lough) showed a 13.7\% difference in peak $C_{P}$. The reasons for this distinction in performance are shown in the time series results. Figure $6 \mathrm{~d}$ shows that restricting the RPM with the PID controller reduces the fluctuation in the TSR over the period of the experiment. As the open-loop control experiences greater fluctuations in TSR, during experiments near peak performance the turbine will be operating at suboptimal TSR in the $C_{P}$-TSR curve. This accounts for the reduction in scatter and higher performance at optimal TSR. However, the PID control with set RPM still results in a fluctuating TSR. In a commercial system where characterising the performance curve isn't the objective, a more appropriate control strategy would use a set TSR, or peak power tracking. This may require knowledge of both the turbine rotational speed and the inflow velocity. This is a consideration for further work. 


\section{Conclusions}

The experimental work presented in this paper successfully completed two experimental campaigns in CNR-INSEAN, Italy and Strangford Lough, Northern Ireland. The continuity of experimental equipment between the two sites provided the opportunity to investigate ADP and ADV calibration agreement with factory settings. It was found that both instruments closely agreed with the factory transformation matrices.

The research has furthered the development of the IEC bin method [23] by the inclusion of a Doppler noise bias correction factor and a method for calculating uncertainties in the derived performance characteristics, with particular attention to uncertainties associated with inflow characterisation.

The work has shown that the effect of unsteady inflow on the derived turbine power performance has a slight detrimental impact of circa $8 \%$. This is in line with the findings of Starzmann et al. [11] and Blackmore et al. [15] and can be considered within the experimental accuracy. To clarify this further will require narrowing the confidence intervals and possible methods of doing this have been suggested.

The two control types, representative of typical strategies in experimental and prototype devices, have shown that a PID feedback controller with set RPM helps achieve a distinctly higher performance curve than the open loop control system, when applied to the turbine operating in unsteady flow conditions such as Strangford Lough. This is critical to consider in experimental design. The fluctuating TSR, as a result of unsteady flow and constrained RPM, remains a weakness in the system if in the presence of large inflow fluctuations. For this reason, it is recognised as a suitable control strategy for characterising a turbine in unsteady flow conditions. Continued development of the PID control is an area of further work, using peak power tracking algorithms and a pre-defined power curve. The inclusion of these strategies will bring the device further in-line with existing industry strategies and make experimental output more relatable to the sector.

Author Contributions: Conceptualization, C.F., I.B., P.J., B.E. and T.W.; Data curation, C.F., I.B. and P.J.; Formal analysis, C.F. and I.B.; Funding acquisition, P.J. and B.E.; Investigation, C.F. and I.B.; Methodology, C.F., I.B., P.J. and B.E.; Project administration, C.F., B.E. and T.W.; Software, C.F. and I.B.; Supervision, B.E. and T.W.; Validation, I.B.; Visualization, C.F. and I.B.; Writing-original draft, C.F.; Writing-review \& editing, I.B., P.J., B.E. and T.W.

Funding: This research was funded by Invest Northern Ireland, through the Centre for Advanced Sustainable Energy (CASE).

Acknowledgments: The authors would like to thank Francesco Salvatore, Luigi Fabbri and all the other CNR-INSEAN staff who supported the work. The authors would also like to thank Cuan Boake of Applied Renewables Research Ltd., Ralf Starzmann of Schottel Hydro and Graeme Mackie of Oceanflow Energy.

Conflicts of Interest: The authors declare no conflict of interest. The funding sponsors had no role in the design of the study; in the collection, analyses, or interpretation of data; in the writing of the manuscript, and in the decision to publish the results.

\section{Nomenclature}

\section{Parameter}

Area of turbine $\left(\mathrm{m}^{2}\right)$

Velocity Bin Identifier

Time Instant Identifier

Depth Profile Bin Identifier

Number of samples

Density $\left(\mathrm{kg} / \mathrm{m}^{3}\right)$

Extracted Power

Extracted Torque

Turbine Radius (m)

Sample Identifier

Extracted Thrust

Mean Velocity (m/s)

Rotational Speed (rad/s)

Symbol
$A$
$i$
$j$
$k$
$n$
$\rho$
$P$
$Q$
$r$
$\mathrm{~s}$
$T$
$\bar{U}$
$\omega$


Standard Deviation

$\sigma$

Two Standard Deviation (95\% confidence interval) $2 \sigma$

\section{Appendix A}

\section{ADP Towing Tank Calibration Results}

To test the calibration equations shown in Section 2.2, the disagreement between Vector and Aquadopp velocity measurements in Strangford Lough were examined over 30 runs. These measurements were completely independently of all those used for the calibration. The inflow velocity in the Strangford was not necessarily well aligned with the turbine axis during all tests, so the magnitudes and the yaw angles for the inflow velocities were analysed. Poorer agreement between the two instruments was found at yaw angles of 15 degrees or more.

In Table A1, the variable $S$ expresses the disagreement between concurrent Vector and Aquadopp velocity measurements, as a percentage. The values predicted using the calibration data alone, as well as those obtained from the validation data, are tabulated.

Table A1. Precision and bias of ADP and ADV.

\begin{tabular}{cccc}
\hline $\begin{array}{c}\text { Variable } S \text { (Percentage Disagreement } \\
\text { between Vector and Aquadopp) }\end{array}$ & $\begin{array}{c}\text { Prediction from } \\
\text { Calibration }\end{array}$ & $\begin{array}{c}\text { Whole } \\
\text { Validation Dataset }\end{array}$ & $\begin{array}{c}\text { Validation for Yaw } \\
\text { within } \pm \text { 15 Degrees }\end{array}$ \\
\hline Bias = Mean $(S)$ & $-0.08 \%$ & $+1.03 \%$ & $+0.27 \%$ \\
\hline Precision = Standard Deviation $(S)$ & $\pm 1.1 \%$ & $\pm 2.53 \%$ & $\pm 2.02 \%$ \\
\hline
\end{tabular}

The Aquadopp is evidently a very good unbiased estimator of mean inflow velocity for yaw angles under 15 degrees.

The validation data utilises effectively 1.7 Aquadopp depth cells, where 5.7 are used over the full swept area. This means that the precision in the inflow velocity expressed as a standard deviation is expected to be very close to $1 \%$ when averaged over the swept area.

\section{Appendix B}

\section{B.1. Deriving Single Measurement for Inflow Velocity}

The IEC 62600:200 technical specification sets out the approach for determining the power performance of a device using ADP inflow data. The 'method of bins' enables the velocities in the shear profile across the projected area of the rotor to be represented as an area weighted and power averaged single point measurement.

Figure A1 illustrates this method, the projected area of the turbine is slices into a series of sections representing the depth bins of the ADP. Meanwhile, the tubular sections represent each sample, or time. For the set-up in the TTT 3 project, each depth bin is $0.25 \mathrm{~m}$ deep and each time period is $1 \mathrm{~s}$. Each section has an area $A_{K}$ and a velocity measurement $U_{i, j, k, n}$ (see nomenclature for definitions).

The IEC approach to obtaining a single value for the flow across the swept area of the turbine during a given test case follows this sequence of equations [23]. Firstly, the power-weighted and area average for the projected area of the turbine for each period is calculated in Equation (A1), and illustrated by the thicker lines in Figure A1.

$$
\hat{U}_{i, j, n}=\left[\frac{1}{A} \times \sum_{k=1}^{s} U_{i, j, k, n}^{3} \times A_{k}\right]^{\frac{1}{3}}
$$

The equation uses the instantaneous velocity measurement in each of profiler depth bins $\left(U_{i, j, k, n}\right)$, which was cubed and weighted by the area of the depth bin $\left(A_{k}\right)$. The sum of these is then divided by the total swept area $(A)$ and cube rooted. This provides the power-weighted current velocity $\left(\hat{U}_{i, j, n}\right)$ for each period.

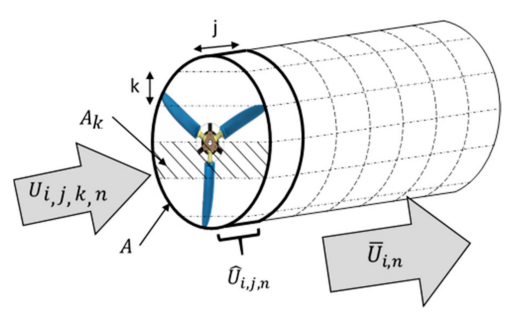

Figure A1. Power-weighted current velocity calculation illustration. 
It is at this point that the adaptation of the IEC 'method of bins' is introduced. All ADP measurements are subject to uncertainty from Doppler noise. The IEC method requires each $1 \mathrm{~s}$ sample at each depth cell to be cubed, as shown in Equation (A1), thus cubing the measurement error from Doppler noise. To correct for this, the Doppler noise bias correction method has been developed. To demonstrate the analytical derivation for the Doppler noise bias correction; let us take $m$ as the mean and $\sigma$ as the standard deviation of a normal variate. The variable $q$ is introduced, which is related to the variance of the distribution as shown in Equation (A2).

$$
\sigma^{2}=m^{2} q
$$

In the case of power measurements derived from ADP data, it is the distribution of the cube of samples, $\left(X_{k}\right)^{3}$, which have been obtained from the normal distribution $N(m, \sigma)$ that is important. The effect of cubing a measurement with an included sampling error was first formally examined by Haldane in statistical biology [31]. Haldane showed that the mean of this resulting distribution exceeds $m^{3}$ by the ratio $R$, as follows in Equation (A3).

$$
R=(1+3 q)=\overline{\left(X_{k}^{3}\right)} / m^{3}
$$

The values of $q$ and $m$, as defined above, are readily obtainable from the ADP data. We have called the ratio $R$ the 'Doppler noise bias', and $R$ can be applied as a correction wherever the cube of a noisy velocity signal is sought and the ratio of $m$ and $\sigma$ is known. For the derivation of the power-weighted, area-averaged velocity, as previously described in Equation (A1), this can now be re-written to include the bias correction factor derived, as shown in Equation (A3). The outcome of this is an unbiased velocity measurement and reduced uncertainty in the propagation of the performance metrics.

$$
\hat{U}_{i, j, n}=\left[\frac{1}{A} \times \sum_{k=1}^{s} \frac{U_{i, j, k, n}^{3} \times A_{k}}{R_{i, k, n}}\right]^{\frac{1}{3}}
$$

The datasets were averaged over periods between 2 and $10 \mathrm{~min}$ for the Strangford Lough testing. For CNR-INSEAN, due to the limited length of the tanks, the maximum averaging period was approximately $90 \mathrm{~s}$; however, given the controlled nature of the experiments in the laboratory this was not considered to be an issue. The mean velocity for the data set $\left(\bar{U}_{i, n}\right)$ is calculated from the power weighted values $\hat{U}_{i, j, n}$ over the time period from $j=1$ to $j=\mathrm{L}$, the length of the run is in seconds. Lastly, the average for all the velocities recorded in the given current velocity bin is calculated. The velocity bin increments were set to $0.10 \mathrm{~ms}^{-1}$ and only flood phase of the tide is considered. These steps are described and equations defined in previous work [13,23].

The turbine's instrumentation as described earlier includes a torque sensor and rotational encoder on the driveshaft behind the rotor. These outputs provide the mechanical power $(P, W)$ of the rotor in advance of drivetrain losses. Power is calculated using Equation (A5).

$$
\dot{P}_{i}=\frac{1}{N_{i}} \sum_{n=1}^{N_{i}} \dot{Q}_{i, n} \times \dot{\omega}_{i, n}
$$

The same velocity bin increments apply here also. When sampled over the same time period as the ADP data, the turbine data has more sample points $(n)$, as it is sampled at $16 \mathrm{~Hz}$ as opposed to the $1 \mathrm{~Hz}$ sample frequency of the ADP. The mechanical power performance can then be calculated using the non-dimensional performance characteristic, $C_{P}$ as previously described in Equations (1) and (2) inserting Equations (A4) and (A5). The water density was set to $1000 \mathrm{~kg} \cdot \mathrm{m}^{-3}$ and $1025 \mathrm{~kg} \cdot \mathrm{m}^{-3}$ for laboratory and field data respectively.

\section{B.2. Propagation of Uncertainty}

Understanding of the propagation of instrument uncertainties is crucial to determining the confidence intervals of derived performance characteristics. Similar studies into the propagation of uncertainty have been conducted in this area before [32]. The previous work showed the significance of uncertainties in the torque, thrust and bending moments when propagated to derive the power performance coefficient. The propagation of inflow uncertainties was not specifically considered by Doman et al., due to the close control afforded by towing tank experiments. For experimental set-ups in real tidal flows, this exception can no longer be made. Therefore, the following section concentrates on the propagation of the velocity uncertainty from the ADP data, through the method of bins, used by the IEC technical specification (TS62600:200).

To ascertain the uncertainty of the derived performance indicators of a tidal turbine, the uncertainty of each variable in the derived performance indicator must be pooled. Equations (A6)-(A8) shows the propagation of uncertainty equation associated with each of the performance indicators.

$$
\begin{gathered}
\sigma_{\mathrm{TSR}}=\mathrm{TSR} \times \sqrt{\left(\frac{\sigma_{\omega}}{\hat{\omega}_{i}}\right)^{2}+\left(\frac{\sigma_{r}}{r}\right)^{2}+\left(\frac{\sigma_{\dot{U}_{i}}}{\dot{U}_{i}}\right)^{2}} \\
\sigma_{C_{P}}=C_{P} \times \sqrt{\left(\frac{\sigma_{Q}}{\hat{Q}_{i}}\right)^{2}+\left(\frac{\sigma_{\omega}}{\dot{\omega}_{i}}\right)^{2}+\left(\frac{\sigma_{\rho}}{\rho}\right)^{2}+\left(\frac{\sigma_{A}}{A}\right)^{2}+\left(\frac{3 \times \sigma_{\dot{U}_{i}}}{\dot{U}_{i}}\right)^{2}}
\end{gathered}
$$




$$
\sigma_{C_{T}}=C_{T} \times \sqrt{\left(\frac{\sigma_{T}}{\hat{T}_{i}}\right)^{2}+\left(\frac{\sigma_{\rho}}{\rho}\right)^{2}+\left(\frac{\sigma_{A}}{A}\right)^{2}+\left(\frac{2 \times \sigma_{\dot{U}_{i}}}{\dot{U}_{i}}\right)^{2}}
$$

As Equations (A7) and (A8) show, the propagated uncertainty is most sensitive to uncertainties in the inflow velocity. The uncertainty variables are derived from the Root Mean Squared (RMS) of bias and precision uncertainties, as shown in other work $[13,32]$. This is the case for all uncertainty parameters derived, with the exception of the inflow velocity uncertainty. The exception to the inflow velocity is due to the correction applied for Doppler noise bias in Equation (A6). This correction accounts for the bias uncertainty, leaving only the precision uncertainty, which is calculated in Equation (A9)

$$
\sigma_{\dot{U}_{i}}=\left(\frac{\sigma}{\sqrt{s}}\right) / \sqrt{n}
$$

\section{References}

1. Department for Buisness, Energy \& Industrial Stragety. Contracts for Difference Second Allocation Round Results. 2017. Available online: https:/ /www.gov.uk/government/publications/contracts-for-differencecfd-second-allocation-round-results (accessed on 20 January 2018).

2. Mason-Jones, A.; O’Doherty, D.M.; Morris, C.E.; O’Doherty, T.; Byrne, C.B.; Prickett, P.W.; Grosvenor, R.I.; Owen, I.; Tedds, S.; Poole, R.J. Non-dimensional scaling of tidal stream turbines. Energy 2012, 44, 820-829. [CrossRef]

3. Clarke, J.A.; Connor, G.; Grant, A.D.; Johnstone, C.M. Design and testing of a contra-rotating tidal current turbine. Proc. Inst. Mech. Eng. Part A J. Power Energy 2007, 221, 171-179. [CrossRef]

4. Gaurier, B.; Germain, G.; Facq, J.V.; Johnstone, C.M.; Grant, A.D.; Day, A.H.; Nixon, E.; Di Felice, F.; Costanzo, M. Tidal energy "Round Robin" tests comparisons between towing tank and circulating tank results. Int. J. Mar. Energy 2015, 12, 87-109. [CrossRef]

5. Mycek, P.; Gaurier, B.; Germain, G.; Pinon, G.; Rivoalen, E. Experimental study of the turbulence intensity effects on marine current turbines behaviour. Part I: One single turbine. Renew Energy 2014, 66, 729-746. [CrossRef]

6. Jeffcoate, P.; Whittaker, T.; Boake, C.; Elsaesser, B. Field tests of multiple 1/10 scale tidal turbines in steady flows. Renew. Energy 2016, 87, 240-252. [CrossRef]

7. Jeffcoate, P.; Elsaesser, B.; Whittaker, T.; Boake, C. Testing Tidal Turbines-Part 1: Steady Towing Tests vs. Tidal Mooring Tests. In Proceedings of the ASRANet International Conference on Offshore Renewable Energy, Glasgow, UK, September 2014; Volume 68, pp. 55-87. Available online: https:/ / pure.qub.ac.uk/ portal/files/11366206/ASRANet_2014_PJeffcoate.pdf (accessed on 20 January 2018).

8. Atcheson, M.; MacKinnon, P.; Elsaesser, B. A large scale model experimental study of a tidal turbine in uniform steady flow. Ocean Eng. 2015, 110, 51-61. [CrossRef]

9. Jeffcoate, P.; Salvatore, F.; Boake, C.; Elsaesser, B.; Vallerano, V. Effect of Submergence on Tidal Turbine Performance. In Proceedings of the 11th European Wave and Tidal Energy Conference, Nantes, France, 6-11 September 2015; pp. 3-9.

10. Jeffcoate, P.; Starzmann, R.; Elsaesser, B.; Scholl, S.; Bischoff, S. Field measurements of a full scale tidal turbine. Int. J. Mar. Energy 2015, 12, 3-20. [CrossRef]

11. Starzmann, R.; Jeffcoate, P.; Scholl, S.; Bischof, S.; Elsaesser, B. Field testing a full-scale tidal turbine Part 1: Power Performance Assessment. In Proceedings of the 11th European Wave and Tidal Energy Conference, Nantes, France, 6-11 September 2015; pp. 1-7.

12. Schmitt, P.; Elsaesser, B.; Bischof, S.; Starzmann, R. Field testing a full-scale tidal turbine Part 2: In-line Wake Effects. In Proceedings of the 11th European Wave and Tidal Energy Conference, Nantes, France, 6-11 September 2015; pp. 1-7.

13. Frost, C.; Benson, I.; Elsäßer, B.; Starzmann, R.; Whittaker, T. Mitigating Uncertainty in Tidal Turbine Performance Characteristics from Experimental Testing. In Proceedings of the European Wave \& Tidal Energy Conference, Cork, Ireland, 27 August 2017.

14. Forbush, D.; Polagye, B.; Thomson, J.; Kilcher, L.; Donegan, J.; McEntee, J. Performance characterization of a cross-flow hydrokinetic turbine in sheared inflow. Int. J. Mar. Energy 2016, 16, 150-161. [CrossRef]

15. Blackmore, T.; Myers, L.E.; Bahaj, A.S. Effects of turbulence on tidal turbines: Implications to performance, blade loads, and condition monitoring. Int. J. Mar. Energy 2016, 14, 1-26. [CrossRef] 
16. European Commission Technology readiness levels (TRL). Horizon 2020 General Annexes; European Commission: Brussels, Belgium, 2015; p. 4995.

17. Mason-Jones, A.; O'Doherty, D.M.; Morris, C.E.; O’Doherty, T. Influence of a velocity profile \& support structure on tidal stream turbine performance. Renew. Energy 2013, 52, 23-30. [CrossRef]

18. Payne, G.S.; Stallard, T.; Martinez, R. Design and manufacture of a bed supported tidal turbine model for blade and shaft load measurement in turbulent flow and waves. Renew. Energy 2017, 107, 312-326. [CrossRef]

19. Harrold, M.J. Experimental and Numerical Assessment of a Tidal Turbine Control Strategy, University of Strathclyde, 2016. Available online: http://ethos.bl.uk/OrderDetails.do?uin=uk.bl.ethos.723008 (accessed on 20 January 2018).

20. Allmark, M.; Grosvenor, R.; Prickett, P. An approach to the characterisation of the performance of a tidal stream turbine. Renew. Energy 2017, 111, 849-860. [CrossRef]

21. Schlipf, D.; Pao, L.Y.; Cheng, P.W. Comparison of Feedforward and Model Predictive Control of Wind Turbines Using LIDAR. In Proceedings of the 2012 IEEE 51st IEEE Conference on Decision and Control (CDC), Maui, HI, USA, 10-13 December 2012; pp. 3050-3055.

22. Johnstone, C.M.; McCombes, T.; Bahaj, A.S.; Myers, L.E.; Holmes, B.; Koefoed, J.P.; Bittencourt, C. EquiMar: Development of Best Practices for the Engineering Performance Appraisal of Wwave and Tidal Energy Converters. In Proceedings of the 9th European Wave and Tidal Energy Conference, Southampton, UK, 5-9 September 2011.

23. IEC/TS 62600-200 Power Performance Assessment of Electricity Producing Tidal Energy Converters Commissioned by: IEC. 2011. Available online: https://webstore.iec.ch/publication/7242 (accessed on 20 January 2018).

24. Clark, T.; Black, K.; Ibrahim, J.; Minns, N.; Fisher, S.; Roc, T.; Hernon, J.; White, R. MRCF-TiME-KS9b Turbulence: Best Practices for Data Processing, Classification and Characterisation of Turbulent Flows. Ocean Array Systems: Edinburgh, UK. 2015. Available online: http://www.oceanarraysystems.com/ publications (accessed on 20 January 2018).

25. Shih, H.H.; Payton, C.; Sprenke, J.; Mero, T. Towing Basin Speed Calibration of Acoustic Doppler Current Profiling Instruments. In Joint Conference on Water Resource Engineering and Water Resources Planning and Management 2000; American Society of Civil Engineers: Reston, VA, USA, 2000; pp. 1-10.

26. Oberg, K.; Mueller, D.S. Validation of Streamflow Measurements Made with Acoustic Doppler Current Profilers. J. Hydraul. Eng. 2007, 133, 1421-1432. [CrossRef]

27. Elsaesser, B.; Torrens-Spence, H.; Schmitt, P.; Kregting, L. Comparison of Four Acoustic Doppler Current Profilers in a High Flow Tidal Environment-Queen's University Belfast Research Portal—Research Directory \& Institutional Repository for QUB. In Proceedings of the 3rd Asian Wave and Tidal Energy Conference, Singapore, 24-28 October 2016.

28. Pao, L.Y.; Johnson, K.E. Control of Wind Turbines. IEEE Control Syst. 2011, 31, 44-62. [CrossRef]

29. Bennett, S. The past of pid controllers. Annu. Rev. Control 2001, 25, 43-53. [CrossRef]

30. Ziegler, J.G.; Nichols, N.B. Optimum Settings for Automatic Controllers. J. Dyn. Syst. Meas. Control 1993, 115, 220. [CrossRef]

31. Haldane, J.B.S. Moments of the distributions of power and products of normal variates. Biometrika 1942, 32, 226-242. [CrossRef]

32. Doman, D.A.; Murray, R.E.; Pegg, M.J.; Gracie, K.; Johnstone, C.M.; Nevalainen, T. Tow-tank testing of a 1/20th scale horizontal axis tidal turbine with uncertainty analysis. Int. J. Mar. Energy 2015, 11, 105-119. [CrossRef]

(C) 2018 by the authors. Licensee MDPI, Basel, Switzerland. This article is an open access article distributed under the terms and conditions of the Creative Commons Attribution (CC BY) license (http:/ / creativecommons.org/licenses/by/4.0/). 